\title{
The sutureless aortic valve at 1 year: A large multicenter cohort study
}

\author{
Theodor Fischlein, MD, PhD, ${ }^{a}$ Bart Meuris, MD, PhD, ${ }^{\mathrm{b}}$ Kavous Hakim-Meibodi, MD, \\ Martin Misfeld, MD, PhD, ${ }^{\mathrm{d}}$ Thierry Carrel, MD, PhD, ${ }^{\mathrm{e}}$ Marian Zembala, MD, PhD, \\ Sara Gaggianesi, DVM ${ }^{\mathrm{g}}$ Francesco Madonna, MD, ${ }^{\mathrm{h}}$ François Laborde, MD, ${ }^{\mathrm{i}}$ Federico Asch, MD, ${ }^{\mathrm{j}}$ and \\ Axel Haverich, MD, PhD, ${ }^{\mathrm{k}}$ on behalf of the CAVALIER Trial Investigators
}

\section{ABSTRACT}

Objective: Sutureless aortic valve replacement (AVR) offers an alternative to standard AVR in aortic stenosis. This prospective, single-arm study aimed to demonstrate safety and effectiveness of a bovine pericardial sutureless aortic valve at 1 year.

Methods: From February 2010 to September 2013, 658 patients (mean age $78.3 \pm 5.6$ years; $40.0 \%$ octogenarian; $64.4 \%$ female; mean Society of Thoracic Surgeons score $7.2 \pm 7.4$ ) underwent sutureless AVR in 25 European centers. Concomitant cardiac procedures were performed in $29.5 \%$ and minimally invasive cardiac surgery in $33.3 \%$.

Results: One-year site-reported event rates were $8.1 \%$ for all-cause mortality, $4.5 \%$ for cardiac mortality, $3.0 \%$ for stroke, $1.9 \%$ for valve-related reoperation, $1.4 \%$ for endocarditis, and $0.6 \%$ for major paravalvular leak. No valve thrombosis, migration, or structural valve deterioration occurred. New York Heart Association class improved at least 1 level in $77.5 \%$ and remained stable (70.4\% New York Heart Association class I or II at 1 year). Mean effective orifice area was $1.5 \pm 0.4 \mathrm{~cm}^{2}$; pressure gradient was $9.2 \pm 5.0 \mathrm{~mm} \mathrm{Hg}$. Left ventricular mass decreased from $138.5 \mathrm{~g} / \mathrm{m}^{2}$ before surgery to $115.3 \mathrm{~g} / \mathrm{m}^{2}$ at 1 year $(P<.001)$. Echocardiographic core laboratory findings confirmed that paravalvular leak was rare and remained stable during follow-up.

Conclusions: The Perceval sutureless valve resulted in low 1-year event rates in intermediate-risk patients undergoing AVR. New York Heart Association class improved in more than three-quarters of patients and remained stable. These data support the safety and efficacy to 1 year of the Perceval sutureless valve in this intermediate-risk population. (J Thorac Cardiovasc Surg 2016;151:1617-26)

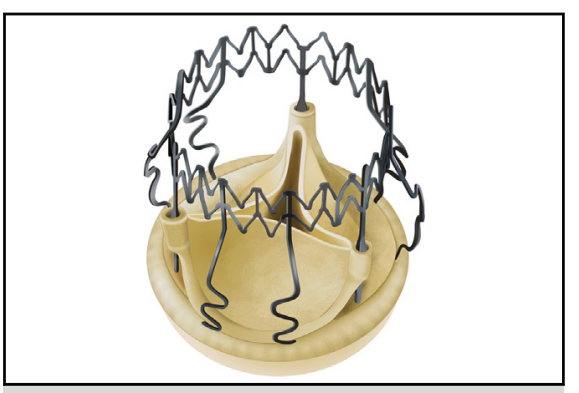

The Perceval sutureless valve is a bioprosthesis with no need of sutures for implantation.

\section{Central Message}

Safety and effectiveness of sutureless aortic valve in a multicenter prospective trial. At 1 year, good clinical outcomes were shown.

\section{Perspective}

This report represents an important 1-year milestone of the clinical and hemodynamic outcomes in the biggest cohort implanted with Perceval sutureless prostheses. Despite the old age (40\% octogenarians) and the risk profile (STS 7.2), 1-year clinical and hemodynamic outcomes are promising, with low rates of cardiac mortality, stroke, endocarditis, major paravalvular leaks, and valve explantations.

See Editorial Commentary page 1627.
The Perceval valve (Sorin Group Italia Srl, Saluggia, Italy) is a self-anchoring, self-expanding, sutureless, surgical aortic bioprosthesis. The valve was designed to facilitate safe and effective implantation of aortic biologic valve prostheses in a rapid fashion with modern deployment

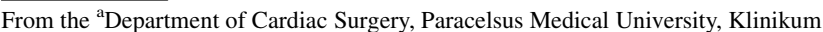
Nürnberg, Nuremberg, Germany; the ${ }^{\mathrm{b}}$ Department of Cardiac Surgery, U.Z. Gasthuisberg, Leuven, Belgium; the ${ }^{\mathrm{c}}$ Department of Thoracic and Cardiovascular Surgery, Herz- und Diabeteszentrum NRW, Ruhr-Universität Bochum, Bad Oeynhausen, and the ${ }^{\mathrm{d}}$ Klinik fur Herzchirurgie, Herzzentrum Universitaet Leipzig, Leipzig, Germany; ${ }^{\mathrm{e}}$ Inselspital, Bern, Switzerland; the ${ }^{\mathrm{f}}$ Department of Cardiac, Vascular and Endovascular Surgery and Transplantology, School of Medicine, Silesian Center for Heart Diseases, Zabrze, Poland; the ${ }^{\mathrm{g} C l i n i c a l}$ Affairs Department, Sorin Group Italia Srl, Saluggia, Italy; the ${ }^{\mathrm{h}}$ Hôpital Cardiologique Du Haut-Leveque, Pessac, France; the ${ }^{\mathrm{i} C a r d i a c}$ Medico-Surgical Department, Institute Mutualiste Montsouris, Paris, France; the ${ }^{\mathrm{j}}$ MedStar Cardiovascular Research Network, Washington Hospital Center, Washington, DC; and the ${ }^{\mathrm{k}}$ Department of Cardiothoracic, Transplantation \& Vascular Surgery, Hannover Medical School, Germany.
}

techniques. ${ }^{1-4}$ Previous reports document that sutureless valves are associated with important advantages relative to standard aortic valve replacement (AVR), such as reduced aortic crossclamp time and cardiopulmonary bypass duration. ${ }^{5}$

\footnotetext{
All funding for this trial was provided by Sorin Group.

Read at the 95th Annual Meeting of The American Association for Thoracic Surgery, Seattle, Washington, April 25-29, 2015.

Clinical trial NCT01368666 registered at www.clinicaltrials.gov.

Received for publication May 11, 2015; revisions received Dec 17, 2015; accepted for publication Dec 29, 2015; available ahead of print Feb 28, 2016.

Address for reprints: Theodor Fischlein, MD, PhD, Department of Cardiac Surgery, Paracelsus Medical University, Klinikum Nürnberg, Breslauer Strasse 201, 90471

Nuremberg, Germany (E-mail: Theodor.Fischlein@klinikum-nuernberg.de). $0022-5223 / \$ 36.00$

Copyright (c) 2016 by The American Association for Thoracic Surgery http://dx.doi.org/10.1016/j.jtcvs.2015.12.064
} 


\begin{tabular}{|c|c|}
\hline \multicolumn{2}{|c|}{ Abbreviations and Acronyms } \\
\hline AVR & $=$ aortic valve replacement \\
\hline PILOT & $\begin{array}{l}=\text { pilot trial to assess the safety of the } \\
\text { Perceval } \mathrm{S} \text { valve at } 30 \text { days after } \\
\text { implant }\end{array}$ \\
\hline PIVOTAL & $\begin{aligned}= & \text { Safety and Performance Study at 3-6 } \\
& \text { months after implant of Perceval S }\end{aligned}$ \\
\hline CAVALIER & $\begin{aligned}= & \text { Safety and Effectiveness Study of } \\
& \text { Perceval S Valve for Extended CE } \\
& \text { Mark }\end{aligned}$ \\
\hline NYHA & $=$ New York Heart Association \\
\hline MICS & $=$ minimally invasive cardiac surgery \\
\hline CI & $=$ confidence interval \\
\hline LV & $=$ left ventricular \\
\hline STS & $=$ Society of Thoracic Surgeons \\
\hline PMI & $=$ pacemaker implantation \\
\hline TAVR & $\begin{array}{l}=\text { transcatheter aortic valve } \\
\text { replacement }\end{array}$ \\
\hline GARY & $=$ German Aortic Registry \\
\hline TAVI & $\begin{aligned}= & \text { transcatheter aortic valve } \\
& \text { implantation }\end{aligned}$ \\
\hline
\end{tabular}

Scanning this QR code will take you to the appendices for this article. To view the AATS 2015 Webcast, see the URL at the end of the article.

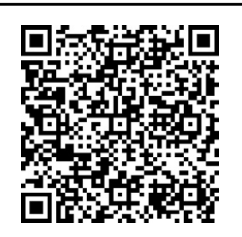

Since 2007, 3 consecutive clinical trials (PILOT, PIVOTAL, and Safety and Effectiveness Study of Perceval $S$ Valve for Extended CE Mark [CAVALIER]) have been carried out to demonstrate the safety and effectiveness of the Perceval valve, at 30 days, 3 to 6 months, and 12 months, respectively. In the first 2 trials, 30 and 150 patients ( $\geq 75$ years old), respectively, were included. The 5-year results from the PILOT study confirmed the performance and safety of this device in a medium- to high-risk population with a small aortic annulus (only sizes $\mathrm{S}$ [19-21 mm] and $\mathrm{M}$ [21-23 $\mathrm{mm}$ ] were available at that time). ${ }^{6}$

A larger cohort (658 patients, $\geq 65$ years old) was included in the CAVALIER trial, and early results showed low rates of mortality and complications, along with favorable hemodynamic outcomes, despite the elderly population. ${ }^{7}$ An Investigational Device Exemption trial was started in the United States in 2013, and 5-year follow-up is ongoing. Subsets of the CAVALIER trial and pooled analyses including data from the PILOT and PIVOTAL trials have been published. ${ }^{7-9} \mathrm{We}$ report here the 1-year clinical and hemodynamic outcomes for the full cohort of the CAVALIER trial.

\section{MATERIALS AND METHODS}

The CAVALIER study is a prospective, single-arm, multicenter European trial (NCT01368666, registered at www.clinicaltrials.org). All enrollees provided signed, informed consent and the study was approved by the ethical committee at each center. Inclusion and exclusion criteria of the study have been described (Table E1). ${ }^{7}$ In brief, eligible patients were at least 65 years old, had a diagnosis of aortic valve stenosis or stenosis with insufficiency, and were eligible for AVR.

The primary end point was the safety and efficacy of the Perceval valve 12 months after implantation, measured as mortality (all-cause and cardiac); percent incidence of morbidity (valvular thrombosis, thromboembolism, hemorrhage, paravalvular leak, endocarditis, hemolysis, structural valve deterioration, nonstructural dysfunction, reoperation, explantation, death, device dislodgment, and device migration); improvement in clinical status (New York Heart Association [NYHA] functional class); and hemodynamic performance according to echocardiographic variables (mean and peak gradient, effective orifice area, indexed effective orifice area, performance index, cardiac output, cardiac index, and degree of regurgitation). Cardiac-related death was defined as all deaths resulting from cardiac causes, including valve-related deaths, sudden unexplained deaths, and deaths from non-valve-related cardiac causes. ${ }^{10}$

Patients were evaluated preoperatively, at implantation, at hospital discharge or within 30 days, and postoperatively, between 3 and 6 months, and at 12 months. Annual evaluations are currently being performed until 5-year follow-up is completed for available patients.

All patients underwent clinical evaluation (NYHA class and cardiac status assessment), blood examination (total blood cell count, creatinine kinase muscle band, international normalized ratio, activated clotting time, serum haptoglobin, plasma free hemoglobin, lactate dehydrogenase, and reticulocytes), and transthoracic echocardiography at each follow-up visit. All echocardiographic examinations were blinded and analyzed by an independent echocardiography core laboratory (Medstar Research, Washington, DC). Peak and mean aortic gradients were calculated from the modified Bernoulli equation.

Hemolysis was defined as the destruction of red blood cells by physical forces as determined by laboratory results. Clinically significant hemolysis was defined as hemolysis requiring reintervention.

An independent clinical events committee adjudicated the primary cause of death, reason for valve explantation, and other serious adverse events according to guidelines. ${ }^{10,11}$ All data were monitored by an independent clinical research organization.

\section{Sizing and Implantation Technique}

The Perceval valve is a bioprosthetic heart valve, CE Marking approved in 2011. The biologic component consists of glutaraldehyde-fixed bovine pericardium treated with homocysteic acid to mitigate calcification. The stent is made of an elastic nickel-titanium alloy covered by Carbofilm (LivaNova, Milan, Italy) to improve biocompatibility. The stent supports the valve and holds it in place without any permanent suture. The valve is collapsed with a proprietary device accessory provided by the manufacturer to reduce the diameter of the prosthesis without damaging the prosthesis leaflets.

Proctoring was done for all institutions at the beginning of the study. Classic sternotomy or a minimally invasive cardiac surgery (MICS) approach was chosen according to the individual surgeon's preferences. Transverse aortotomy approximately $3.5 \mathrm{~cm}$ above the aortic annulus was performed to accommodate the height of the prosthetic stent. After removal of the native valve leaflets, annular decalcification was performed, and the valve was sized with product-specific sizers. At the beginning of the study, only eccentric or bulky protruding intraluminal calcifications were removed, rather than performing complete intra-annular decalcification. With experience, we learned that thorough decalcification of the aortic annulus should be performed to optimize valve seating and prevent postoperative paravalvular leakage. All the investigators were familiarized with the sizing techniques as described 
in the device's instructions for use, in particular to avoid oversizing in every case. The dual-ended Perceval sizers include a transparent obturator and a white obturator; the valve is appropriately sized to the correspondingly labeled sizer with a transparent obturator that can be passed through the annulus and a white obturator that cannot be made to pass through the annulus.

To ensure correct positioning of the prosthesis, 3 guiding sutures were used as a reference for accurate alignment of the inflow section of the prosthesis with the insertion plane of the native leaflets. These sutures were positioned at the nadir of each valve sinus as single annular sutures and then passed through the corresponding eyelets in the prosthetic inflow ring. The valve prosthesis was loaded onto the delivery device through a unique collapsing mechanism and then inserted into the level of the aortic annulus. The valve was released first at the inflow section, then at the outflow, followed by postimplantation dilation with a specifically designed low-pressure balloon catheter (4 atm). Once the prosthesis had been deployed completely, the guiding sutures were removed, and the aortotomy was closed in the traditional fashion. Treatment with warfarin or low-molecular weight heparin was recommended according to the study protocol for at least 3 months. Investigators could choose the most appropriate pharmacologic treatments according their patients' clinical status or their centers' routine protocols.

\section{Statistical Analysis}

Statistical analysis was performed on all cases (database frozen in December 2014). Categoric variables are reported as absolute and relative frequencies. For continuous data, means and SDs were calculated. Cumulative survival and freedom from events were estimated with the Kaplan-Meier method, with 95\% confidence intervals (CI). The Wilcoxon signed-rank test was applied to compare echocardiographic data regarding left ventricular (LV) mass reduction with time. Statistical analyses were performed with SAS software (version 9.2; SAS Institute Inc, Cary, NC).

\section{RESULTS}

From February 2010 to September 2013, a total of 815 consecutive patients were enrolled in 25 centers in 8 European countries. Implantation of the Perceval valve was not attempted in 157 of the 815 enrolled patients because of the lack of availability of appropriately sized valves in 66 cases $(42 \%$; size XL, $25-27 \mathrm{~mm}$, was introduced into the study in April 2012) and the presence of intraoperative exclusion criteria in the remainder, most commonly congenital bicuspid valve (16 patients, $10 \%$ ), annulus/sinotubular junction ratio greater than $1.3(12$ patients, $8 \%)$, and aortic annulus diameter larger than $27 \mathrm{~mm}$ (7 patients, $4 \%$ ) or smaller than $19 \mathrm{~mm}$ (3 patients, $2 \%$ ). The study population was therefore composed of 658 patients (Figure E1). Of 577 surviving patients without explantations, 12 withdrew from the study and 2 were unavailable for follow-up; at 1 year, the complete study population accounted for $551 \mathrm{pa}-$ tients $(100 \%)$; however, 1-year follow-up data were available for $97 \%$ of patients $(n=537)$.

Baseline preoperative demographic characteristics and intraoperative data are reported in Table 1. Mean age of the population was $78.3 \pm 5.6$ years (range 61.6-92.6 years), and $40.0 \%$ were at least 80 years old. Mean Society of Thoracic Surgeons (STS) score was 7.2 \pm 7.4 , and 64.4\% were female. According to the study protocol, pure aortic regurgitation was an exclusion criterion for the implant procedure; however, in 2 patients with aortic regurgitation, the Perceval valve was implanted at the surgeon's discretion, and these patients are included in this cohort.

The valve was successfully implanted in 628 patients (95.4\%). In 30 patients, implantation failed and the Perceval valve was removed during the original procedure. Reasons for implant failure were dislodgment $(\mathrm{n}=8)$, central leak or paravalvular leakage $(\mathrm{n}=14)$, malposition $(n=4)$, suspected aortic tear $(n=1)$, multiple unsuccessful attempts $(\mathrm{n}=2)$, and presence of endocarditis with abscess $(n=1)$. In the last case, the patient did not meet 2 inclusion criteria (age $\geq 65$ years; aortic valve stenosis or stenosis with insufficiency) and met 1 exclusion criterion (previous implantation of valve prostheses or annuloplasty ring not being replaced by the study valve). This case was within the compassionate use of the Perceval valve for a patient who had previously undergone multiple valve operations. Eventually, the Perceval valve was replaced with a different biologic valve because of the presence of an abscess, but the patient died the same day as surgery.

In more than $80 \%$ of cases, a size $\mathrm{M}(21-23 \mathrm{~mm})$ or size $\mathrm{L}$ (23-25 mm) valve was implanted. Concomitant cardiac procedures were performed in $29.5 \%$ of patients $(n=194)$, 154 of whom underwent coronary aortic bypass grafting. MICS was performed in $33.3 \%(n=219)$ of patients (216 patients underwent ministernotomy, and 3 underwent right anterior minithoracotomy).

Mean crossclamp times were 33.2 minutes for cases in which median sternotomy was performed and $38.8 \mathrm{~min}$ for MICS in patients undergoing isolated AVR.

At discharge, $41.4 \%$ of patients (254/614) were taking warfarin alone; $28.5 \%$ (175/614) were prescribed anticoagulants in combination with aspirin or other antiplatelet treatment; and $24.4 \%(150 / 614)$ of patients were taking aspirin alone. The percentage of patients receiving warfarin therapy declined during follow-up $(18.8 \% ; 101 / 536)$; in contrast, use of aspirin rose to $58.2 \%(312 / 536)$.

\section{End Points}

Mortality and morbidity event rates are detailed in Table 2. One-year overall survival was $91.7 \%$ (95\% CI, $89.6 \%-93.9 \%$ ), and freedom from cardiac death was 95.4\% (95\% CI 93.8\%-97.1\%). All-cause mortalities were $4.8 \%$ for isolated procedures and $3.3 \%$ (2.9\% in AVR plus coronary artery bypass grafting) for concomitant cardiac procedures. Figure 1 shows all-cause and valverelated mortalities out to 1 year.

Endocarditis was reported in $1.4 \%$ of patients $(\mathrm{n}=9)$ between 8 and 231 days after implant (mean interval, 97.0 days). One patient died 13 days postoperatively of sepsis and disseminated intravascular coagulation; 2 patients (1 with recurrence) were treated with antibiotics, and their symptoms resolved; and 5 patients underwent reoperation to have the valve explanted, with 3 of them 
TABLE 1. Baseline operative and intraoperative data

\begin{tabular}{|c|c|}
\hline $\mathrm{N}$ & 658 \\
\hline Age $(y$, mean \pm SD and range $)$ & $78.3 \pm 5.6(61.6-92.6)$ \\
\hline Patients $\geq 80$ y old & $263(40.0 \%)$ \\
\hline \multicolumn{2}{|l|}{ Sex } \\
\hline Female & $424(64.4 \%)$ \\
\hline Male & $234(35.6 \%)$ \\
\hline $\mathrm{BSA}\left(\mathrm{m}^{2}\right.$, mean $\pm \mathrm{SD}$ and range $)$ & $1.8 \pm 0.2(1.0-2.4)$ \\
\hline \multicolumn{2}{|l|}{ NYHA functional class } \\
\hline I & $22(3.3 \%)$ \\
\hline II & $198(30.1 \%)$ \\
\hline III & $386(58.7 \%)$ \\
\hline IV & $32(4.9 \%)$ \\
\hline Not assessable & $20(3.0 \%)$ \\
\hline \multicolumn{2}{|l|}{ euroSCORE } \\
\hline Mean \pm SD & $10.2 \pm 7.8$ \\
\hline Range & $1.2-75.3$ \\
\hline Median and IQR & $7.9(5.6-11.4)$ \\
\hline \multicolumn{2}{|l|}{ STS score } \\
\hline Mean \pm SD & $7.2 \pm 7.4$ \\
\hline Range & $0.8-50.0$ \\
\hline Median and IQR & $4.1(2.4-9.1)$ \\
\hline \multicolumn{2}{|l|}{ Cardiac rhythm } \\
\hline Sinus & $559(85.5 \%)$ \\
\hline Atrial fibrillation & $52(8.0 \%)$ \\
\hline Other & $22(3.4 \%)$ \\
\hline Paced & $21(3.2 \%)$ \\
\hline \multicolumn{2}{|l|}{ Previous cardiovascular surgery* } \\
\hline CABG & $13(10.2 \%)$ \\
\hline PCI & $78(61.4 \%)$ \\
\hline Pacemaker & $33(26.0 \%)$ \\
\hline Aortic valve replacement & $10(7.9 \%)$ \\
\hline Valve repair with ring & $1(0.8 \%)$ \\
\hline Other & $10(7.9 \%)$ \\
\hline \multicolumn{2}{|l|}{ Risk factors } \\
\hline Systemic hypertension & $551(83.7 \%)$ \\
\hline Diabetes & $191(29.0 \%)$ \\
\hline Insulin-dependent diabetes & $63(9.6 \%)$ \\
\hline Active smokers & $31(4.7 \%)$ \\
\hline Extracardiac arteriopathy & $112(17 \%)$ \\
\hline Chronic lung disease & $103(15.7 \%)$ \\
\hline Renal insufficiency & $97(14.8 \%)$ \\
\hline Cerebrovascular disease & $75(11.4 \%)$ \\
\hline \multicolumn{2}{|l|}{ Surgical approach } \\
\hline Median sternotomy & $439(66.7 \%)$ \\
\hline Minimally invasive approach & $219(33.3 \%)$ \\
\hline \multicolumn{2}{|l|}{ Aortic valve lesion } \\
\hline Stenosis & $430(65.3 \%)$ \\
\hline Stenosis and regurgitation & $226(34.3 \%)$ \\
\hline Regurgitation & $2(0.3 \%)$ \\
\hline \multicolumn{2}{|l|}{ Valve size } \\
\hline $\mathrm{S}(21 \mathrm{~mm})$ & $84(12.8 \%)$ \\
\hline $\mathrm{M}(23 \mathrm{~mm})$ & $290(44.1 \%)$ \\
\hline $\mathrm{L}(25 \mathrm{~mm})$ & $255(38.8 \%)$ \\
\hline $\mathrm{XL}(27 \mathrm{~mm})$ & $29(4.4 \%)$ \\
\hline \multicolumn{2}{|l|}{ Concomitant cardiac procedures $\dagger$} \\
\hline CABG & $154(23.4 \%)$ \\
\hline
\end{tabular}

TABLE 1. Continued

\begin{tabular}{lr}
\hline Septal myectomy & $22(3.3 \%)$ \\
Atrial fibrillation treatment & $20(3.0 \%)$ \\
Tricuspid valve repair & $7(1.1 \%)$ \\
Congenital defect closure & $3(0.5 \%)$ \\
Other & $4(0.6 \%)$ \\
\hline
\end{tabular}

All data are numbers and percentages of patients unless otherwise specified. $S D$, Standard deviation; BSA, body surface area; NYHA, New York Heart Association; euroSCORE, European System for Cardiac Operative Risk Evaluation; $I Q R$, interquartile range; STS, Society of Thoracic Surgeons; CABG, coronary artery bypass grafting, PCI, percutaneous coronary intervention. *Patients may have more than 1 previous intervention. †Patients may have multiple etiologies or concomitant surgical procedures.

dying after surgery. One patient, who did not undergo device explantation, died of endocarditis.

The incidence of primary paravalvular leaks reported by the centers was $1.1 \%$ (Table 2$)$. Major $(\geq+3)$ primary paravalvular leak occurred in $0.6 \%$ of cases, with all leading to explantation. Twelve explantations $(1.9 \%)$ were reported within 1 year for the following conditions: endocarditis $(\mathrm{n}=5)$, valvular regurgitation $(\mathrm{n}=1)$, major primary paravalvular leak $(n=4)$, aorta-right ventricular fistula $(n=1)$, and tear of aortic annulus and LV outflow tract $(\mathrm{n}=1)$. Stroke occurred in $3.0 \%$ of cases. Figure 2 shows the incidence curves for explantation, endocarditis, major primary paravalvular regurgitation, and stroke. The 1-year freedoms from all-cause explantation, endocarditis, major primary paravalvular regurgitation, and stroke were $98.0 \% \quad(95 \% \quad$ CI, $96.9 \%-99.1 \%), \quad 98.5 \% \quad(95 \% \quad$ CI, $97.5 \%-99.5 \%), 99.3 \%(95 \% \mathrm{CI}, 98.7 \%-100.0 \%)$, and 96.7\% (95\% CI, 95.3\%-98.1\%), respectively.

No cases of valve thrombosis, migration, or structural valve deterioration were reported (Table 2). The 1-year incidence of pacemaker implantation (PMI) as a result of third-degree atrioventricular block was $9.6 \%$.

NYHA functional class improved by at least 1 level in $77.5 \%$ of patients and remained stable during follow-up $(60.3 \%$ of patients were in NYHA functional class III or IV preoperatively, whereas $70.4 \%$ were in NYHA functional class I or II at 1 year).

Eight cases of hemolysis were reported, 2 of which required transfusion and were classified as clinically significant. Other hematologic data are reported in Table E2.

Rates of paravalvular leak alone (confirmed by the echocardiographic core laboratory) remained stable between discharge and 1 year (Table 3). At 1 year, $99.5 \%$ of patients were free from hemodynamically significant central regurgitation (moderate regurgitation, $0.5 \%$; severe regurgitation, $0 \%$ ), whereas mild central regurgitation was present in $20.3 \%$.

At 1 year, the echocardiographically determined mean effective orifice area was $1.5 \pm 0.4 \mathrm{~cm}^{2}$, and the aortic valve pressure gradient was $9.2 \pm 5.0 \mathrm{~mm} \mathrm{Hg}$. LV mass index decreased from $138.0 \pm 36.1 \mathrm{~g} / \mathrm{m}^{2}$ before surgery to $115.3 \pm 34.2 \mathrm{~g} / \mathrm{m}^{2}$ at 1 year $(P<.001$; Table 4$)$. 
TABLE 2. Mortality and morbidity events early $(\leq 30 \mathrm{~d})$, late $(>30 \mathrm{~d})$, at 6 months, and at 1 year after implantation

\begin{tabular}{|c|c|c|c|c|}
\hline & Early $(\leq \mathbf{3 0} \mathrm{d})$ & Late $(>\mathbf{3 0} \mathbf{d})$ & Total at $6 \mathrm{mo}(0-180 \mathrm{~d})$ & Total at 1 y $(0-365 d)$ \\
\hline $\mathrm{N}$ & 628 & 599 & 628 & 628 \\
\hline Deaths & $23(3.7 \%)$ & $28(4.7 \%)$ & $42(6.7 \%)$ & $51(8.1 \%)$ \\
\hline Cardiac-related deaths & $16(2.5 \%)$ & $12(2.0 \%)$ & $25(4.0 \%)$ & $28(4.5 \%)$ \\
\hline Non-cardiac-related deaths & $7(1.1 \%)$ & $16(2.7 \%)$ & $17(2.7 \%)$ & $23(3.7 \%)$ \\
\hline Explantation & $6(0.9 \%)$ & $6(1.0 \%)$ & $12(1.9 \%)$ & $12(1.9 \%)$ \\
\hline Thromboembolism & $27(4.3 \%)$ & $11(1.8 \%)$ & $36(5.7 \%)$ & $39(6.2 \%)$ \\
\hline Stroke & $14(2.2 \%)$ & $5(0.8 \%)$ & $18(2.9 \%)$ & $19(3.0 \%)$ \\
\hline Primary paravalvular leak & $5(0.8 \%)$ & $2(0.3 \%)$ & $6(0.9 \%)$ & $7(1.1 \%)$ \\
\hline Major $(\geq+3)$ & $3(0.5 \%)$ & $1(0.2 \%)$ & $4(0.6 \%)$ & $4(0.6 \%)$ \\
\hline Minor $(\leq+2)$ & $2(0.4 \%)$ & $1(0.2 \%)$ & $2(0.4 \%)$ & $3(0.5 \%)$ \\
\hline Secondary paravalvular leak & $1(0.2 \%)$ & $1(0.2 \%)$ & $2(0.4 \%)$ & $2(0.3 \%)$ \\
\hline Intraprosthetic regurgitation & $3(0.5 \%)$ & $0(0 \%)$ & $3(0.5 \%)$ & $3(0.5 \%)$ \\
\hline Major $(\geq+3)$ & $1(0.2 \%)$ & $0(0 \%)$ & $1(0.2 \%)$ & $1(0.2 \%)$ \\
\hline Minor $(\leq+2)$ & $2(0.4 \%)$ & $0(0 \%)$ & $2(0.4 \%)$ & $2(0.4 \%)$ \\
\hline Endocarditis & $1(0.2 \%)$ & $8(1.3 \%)$ & $7(1.1 \%)$ & $9(1.4 \%)$ \\
\hline Hemolysis (clinically significant) & $1(0.2 \%)$ & $1(0.2 \%)$ & $2(0.4 \%)$ & $2(0.3 \%)$ \\
\hline Structural valve deterioration & $0(0 \%)$ & $0(0 \%)$ & $0(0 \%)$ & $0(0 \%)$ \\
\hline Valve thrombosis & $0(0 \%)$ & $0(0 \%)$ & $0(0 \%)$ & $0(0 \%)$ \\
\hline Third-degree AV block leading to pacemaker implantation & $51(8.1 \%)$ & $9(1.5 \%)$ & $55(8.8 \%)$ & $60(9.6 \%)$ \\
\hline
\end{tabular}

All data are numbers and percentages of patients. $A V$, Atrioventricular.

\section{DISCUSSION}

In this prospective, single-arm, European trial in patients at least 65 years old requiring AVR, rates of allcause and cardiac-related death at 12 months after implantation of the Perceval valve were $8.2 \%$ and $4.5 \%$, respectively. Event rates for other outcomes, including explantation, perivalvular leak, endocarditis, and hemolysis, were low, and no patients had structural valve deterioration or valve thrombosis. The Perceval valve showed good hemodynamic performance, with stable reduction of gradients in all valve sizes and an increase in valve effective orifice area, leading to a significant regression in LV mass $(P<.001)$.

\section{Incidence of all-cause mortality at one year}

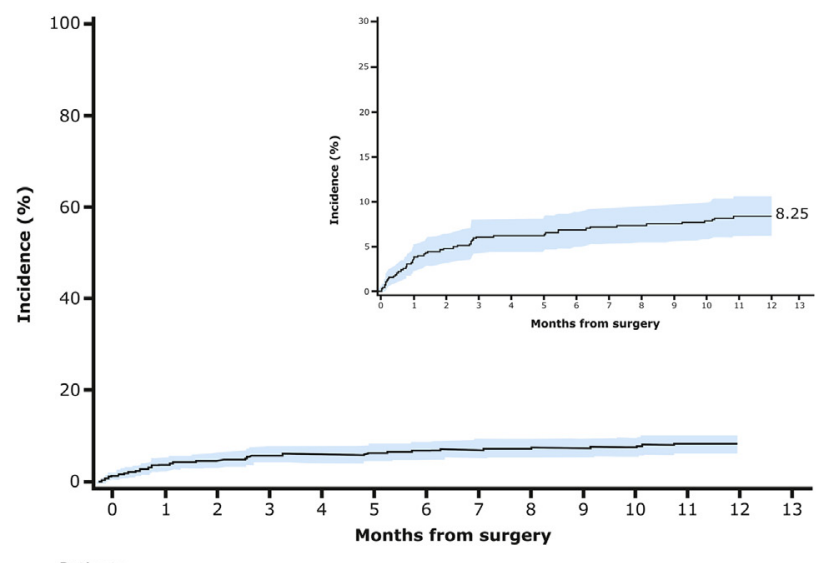

Patients

$\begin{array}{llllllllllllll}\text { at risk } & 628 & 599 & 591 & 581 & 578 & 575 & 568 & 565 & 563 & 559 & 556 & 551 & 525\end{array}$
Importantly, paravalvular leak was very rare and remained stable between discharge and 1 year, which is likely the result of precise annular débridement (the main difference between a sutureless valve like Perceval and transcatheter AVR [TAVR]), allowing for a good apposition of the stent. The design of the prosthesis, which features a conformable stent and pericardial sealing collar, was also key in preventing paravalvular leak.

Mild central regurgitation read by the echocardiographic core laboratory was noted to be increased at 1-year followup, however, hemodynamically significant central aortic regurgitation was negligible. This finding did not translate into a worsening of the patients' clinical status or into any

\section{Incidence of cardiac mortality at one year}

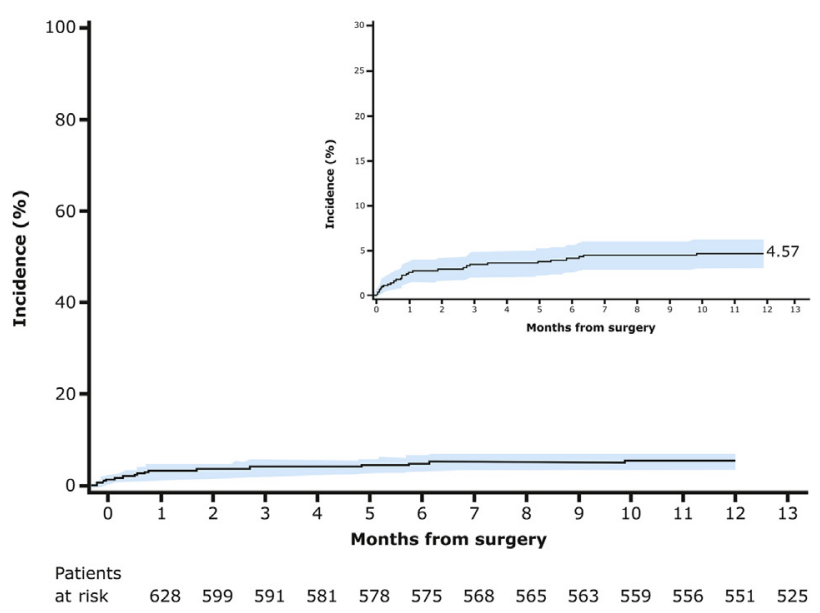

FIGURE 1. Incidence curves for all-cause and valve-related mortality. 
Incidence of explant at one year

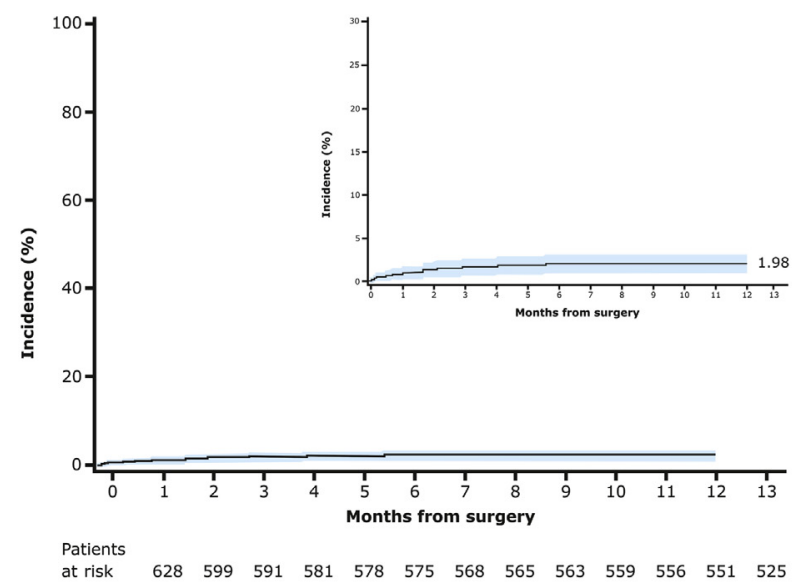

Incidence of major primary paravalvular leak at one year

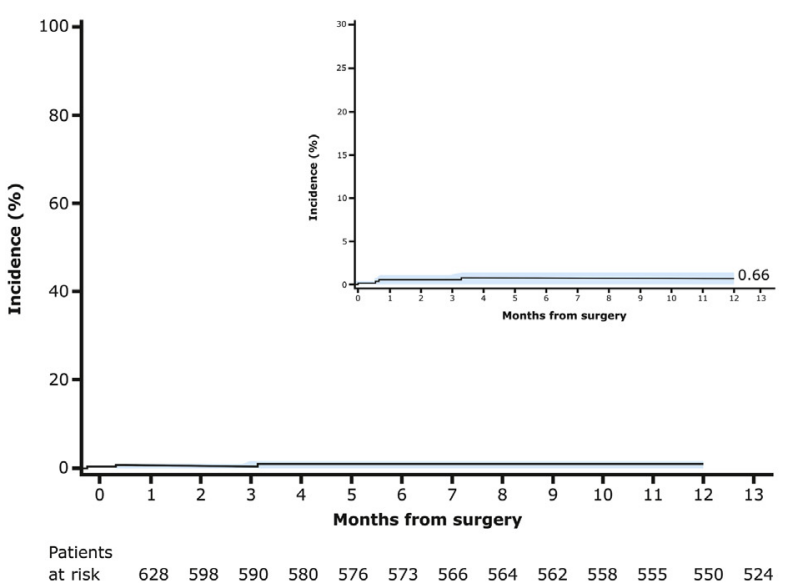

Incidence of endocarditis at one year

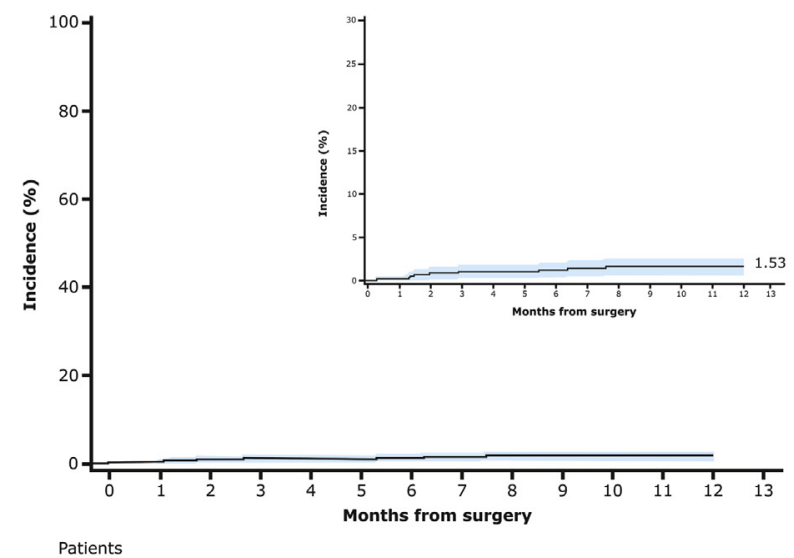

$\begin{array}{llllllllllllll}\text { at risk } & 628 & 599 & 589 & 580 & 577 & 574 & 568 & 565 & 562 & 558 & 555 & 550 & 524\end{array}$

Incidence of thromboembolism at one year

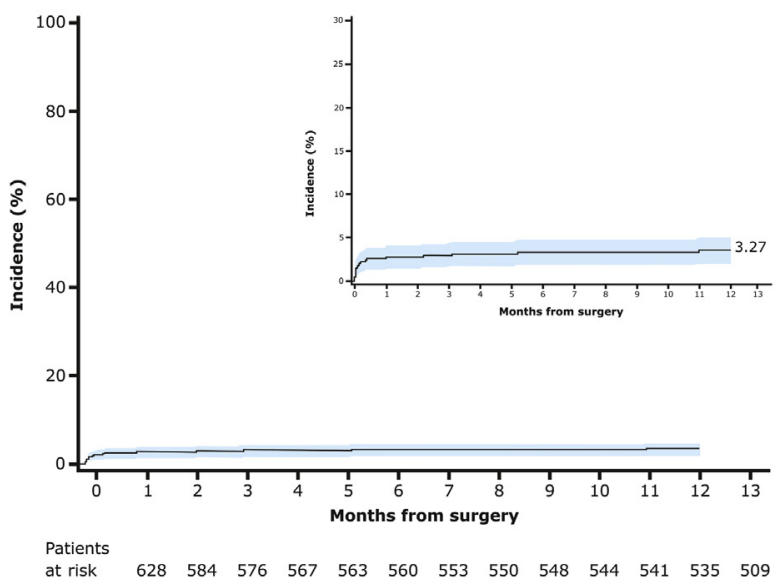

FIGURE 2. Incidence curves for explantation, endocarditis, major primary paravalvular regurgitation, and stroke.

increased rate of valve explantations or valve-related adverse events at 12 months. Indeed, a marked and stable improvement in NYHA class was observed for $77.5 \%$ of the patients.

A recent study reported pooled clinical and hemodynamic data from three studies (PILOT, PIVOTAL, CAVALIER), and included data from 700 patients followed up for 5 years. ${ }^{9}$ Our data contribute further to these results, providing more contemporary (with the database frozen in 2014 vs 2012) and complete information on clinical events at 12 months. Whereas only a limited number of patients from the CAVALIER cohort contributed to 1-year followup in the pooled analysis, ${ }^{9}$ we report the findings from the overall cohort of 628 patients.

The rate of procedural success was high in this study, with only $5 \%$ of patients not receiving the study device. Initial implantation failure in 30 patients may be related to an early learning curve, especially at the start of the study, when the Perceval valve presented a new technology in cardiac surgery. Anecdotally, in our daily practice, we have observed a decrease in the failure rate since the introduction of sutureless and rapid-deployment valves, corresponding to increasing experience with this new technology. Phan and colleagues ${ }^{5}$ found in a meta-analysis a significant negative correlation between the rate of paravalvular leak and the midpoint of the combined studies, suggesting that this complication is a function of the learning curve and is likely to decrease further as surgeons become more familiar with the device.

Sizing and proper annular decalcification are crucial steps in the management of sutureless valves. Improper sizing may result in paravalvular leakage, central aortic regurgitation, dislodgment, and valve migration. Complete and thorough decalcification of the aortic annulus helps to 
TABLE 3. Postoperative valve regurgitation by severity and location according to echocardiographic core laboratory evaluation

\begin{tabular}{lccc}
\hline & Discharge & 3-6 mo & 12 mo \\
\hline $\begin{array}{l}\text { Overall patients with available } \\
\text { echocardiographic }\end{array}$ & 517 & 445 & 433 \\
$\quad$ examination & & & \\
None or trace & $396(76.6 \%)$ & $325(73.0 \%)$ & $289(66.7 \%)$ \\
Paravalvular leak & & & \\
$\quad$ Mild & $16(3.1 \%)$ & $18(4.0 \%)$ & $12(2.8 \%)$ \\
Moderate & $0(0.0 \%)$ & $2(0.4 \%)$ & $2(0.5 \%)$ \\
Severe & $0(0.0 \%)$ & $0(0.0 \%)$ & $0(0.0 \%)$ \\
Not evaluable & $1(0.2 \%)$ & $1(0.2 \%)$ & $0(0.0 \%)$ \\
Central regurgitation & & & \\
$\quad$ Mild & $49(9.5 \%)$ & $72(16.2 \%)$ & $88(20.3 \%)$ \\
Moderate & $3(0.6 \%)$ & $0(0.0 \%)$ & $2(0.5 \%)$ \\
Severe & $0(0.0 \%)$ & $0(0.0 \%)$ & $0(0.0 \%)$ \\
$\quad$ Not evaluable & $0(0.0 \%)$ & $0(0.0 \%)$ & $1(0.2 \%)$ \\
Both paravalvular leak and central regurgitation & & \\
$\quad$ Mild & $11(2.1 \%)$ & $10(2.2 \%)$ & $8(1.8 \%)$ \\
Moderate & $2(0.4 \%)$ & $3(0.7 \%)$ & $7(1.6 \%)$ \\
Severe & $1(0.2 \%)$ & $0(0.0 \%)$ & $3(0.7 \%)$ \\
$\quad$ Not evaluable & $0(0.0 \%)$ & $1(0.2 \%)$ & $1(0.2 \%)$ \\
\hline
\end{tabular}

All data are numbers and percentages of patients.

prevent postoperative paravalvular leakage. Moreover, preimplantation echocardiographic evaluations are of paramount importance to exclude potential anatomic contraindications, such as aortic root dilatation and an annulus/sinotubular junction ratio greater than 1.3. According to the manufacturer's instructions, surgeons must avoid undersizing or oversizing the prosthesis. Undersizing could lead to migration, whereas oversizing could lead to excessive compression or rupture of the aorta, stent invagination, fatal arrhythmia or hemorrhage, regurgitation, or altered hemodynamics. In case of doubt, the most experienced proctors and Perceval users prefer a slight undersizing. To date, no cases of migration have been reported.

The 1-year all-cause mortalities for isolated (4.8\%) and concomitant cardiac procedures $(2.9 \%)$ are similar to those reported in the German Aortic Registry (GARY), in which 1 -year mortality was $6.7 \%$ in the conventional surgical group undergoing isolated AVR. ${ }^{12}$ The incidence of stroke $(3.0 \%)$ is also in concert with GARY registry, which reported 1-year stroke rates of 3.0\% in patients undergoing isolated AVR and 4.5\% in those undergoing combined surgical AVR. ${ }^{12}$ In our series, the incidence of paravalvular leak reported by the participating centers was low and was consistent with the expected performance of the Perceval valve. $^{2,3,5,6}$

The incidence of valve-related reoperation at 1 year was $1.9 \%$ in this study. One patient immediately returned to the operating room for repair of aortic bleeding and had the study valve explanted and replaced with a nonstudy prosthesis. Bleeding was caused by an aortic tear below the right

TABLE 4. Hemodynamic data from preoperative to 1-year visit

\begin{tabular}{|c|c|c|c|c|}
\hline & Preoperative & Discharge & 3 to $6 \mathrm{mo}$ & $12 \mathrm{mo}$ \\
\hline \multicolumn{5}{|l|}{ Overall } \\
\hline Mean gradient (mm Hg) & $45.0 \pm 15.9$ & $10.3 \pm 4.5$ & $8.9 \pm 4.1$ & $9.2 \pm 5.0$ \\
\hline Peak gradient (mm Hg) & $73.5 \pm 24.9$ & $19.4 \pm 8.1$ & $16.8 \pm 7.0$ & $17.1 \pm 8.7$ \\
\hline Effective orifice area $\left(\mathrm{cm}^{2}\right)$ & $0.7 \pm 0.2$ & $1.5 \pm 0.4$ & $1.5 \pm 0.3$ & $1.5 \pm 0.4$ \\
\hline LV mass index $\left(\mathrm{g} / \mathrm{m}^{2}\right)$ & $138.0 \pm 36.1$ & $134.4 \pm 36.9$ & $122 \pm 33.8$ & $115.3 \pm 34.2$ \\
\hline \multicolumn{5}{|l|}{ Size $\mathrm{S}(21 \mathrm{~mm})$} \\
\hline Mean gradient $(\mathrm{mm} \mathrm{Hg})$ & $45.6 \pm 15.4$ & $11.2 \pm 5.3$ & $9.5 \pm 4.7$ & $10.1 \pm 4.2$ \\
\hline Peak gradient (mm Hg) & $74.3 \pm 23.6$ & $20.9 \pm 9.3$ & $18.4 \pm 7.7$ & $18.8 \pm 7.5$ \\
\hline Effective orifice area $\left(\mathrm{cm}^{2}\right)$ & $0.7 \pm 0.2$ & $1.4 \pm 0.4$ & $1.3 \pm 0.3$ & $1.3 \pm 0.3$ \\
\hline LV mass index $\left(\mathrm{g} / \mathrm{m}^{2}\right)$ & $131.6 \pm 32.2$ & $124.6 \pm 38.6$ & $110.9 \pm 35.1$ & $103.5 \pm 32.3$ \\
\hline \multicolumn{5}{|l|}{ Size M (23 mm) } \\
\hline Mean gradient (mm Hg) & $45.1 \pm 15.8$ & $10.7 \pm 4.6$ & $9.3 \pm 4.5$ & $9.4 \pm 5.6$ \\
\hline Peak gradient (mm Hg) & $73.1 \pm 24.7$ & $19.8 \pm 8.0$ & $17.4 \pm 7.6$ & $17.5 \pm 9.9$ \\
\hline Effective orifice area $\left(\mathrm{cm}^{2}\right)$ & $0.7 \pm 0.2$ & $1.4 \pm 0.3$ & $1.4 \pm 0.3$ & $1.5 \pm 0.4$ \\
\hline LV mass index $\left(\mathrm{g} / \mathrm{m}^{2}\right)$ & $135.2 \pm 35.2$ & $130.0 \pm 35.5$ & $120.5 \pm 34.5$ & $111.7 \pm 34.5$ \\
\hline \multicolumn{5}{|l|}{ Size L (25 mm) } \\
\hline Mean gradient (mm Hg) & $44.9 \pm 16.4$ & $9.7 \pm 4.0$ & $8.2 \pm 3.2$ & $8.5 \pm 4.6$ \\
\hline Peak gradient (mm Hg) & $73.9 \pm 25.8$ & $18.5 \pm 7.7$ & $15.4 \pm 5.5$ & $16.0 \pm 7.8$ \\
\hline Effective orifice area $\left(\mathrm{cm}^{2}\right)$ & $0.7 \pm 0.2$ & $1.5 \pm 0.4$ & $1.6 \pm 0.4$ & $1.5 \pm 0.4$ \\
\hline LV mass index $\left(\mathrm{g} / \mathrm{m}^{2}\right)$ & $143.3 \pm 38.1$ & $139.5 \pm 36.6$ & $127.0 \pm 31.1$ & $120.4 \pm 32.7$ \\
\hline \multicolumn{5}{|l|}{ Size XL (27 mm) } \\
\hline Mean gradient (mm Hg) & $43.4 \pm 15.9$ & $9.9 \pm 4.5$ & $9.3 \pm 4.2$ & $10.0 \pm 4.5$ \\
\hline Peak gradient (mm Hg) & $70.4 \pm 24.9$ & $18.7 \pm 8.4$ & $17.8 \pm 7.7$ & $17.9 \pm 6.6$ \\
\hline Effective orifice area $\left(\mathrm{cm}^{2}\right)$ & $0.7 \pm 0.2$ & $1.8 \pm 0.5$ & $1.5 \pm 0.2$ & $1.5 \pm 0.4$ \\
\hline LV mass index $\left(\mathrm{g} / \mathrm{m}^{2}\right)$ & $133.6 \pm 29.5$ & $165.3 \pm 40.3$ & $129.5 \pm 40.0$ & $133.5 \pm 37.1$ \\
\hline
\end{tabular}

Data are mean $\pm \mathrm{SD}$. $L V$, Left ventricular. 
coronary ostium after extensive decalcification of the annulus. Five early explantations were performed at a mean of 13.8 (range 2-30) days after implantation: 3 for significant paravalvular leak, 1 for significant central regurgitation discovered during follow-up echocardiography, and 1 for undersizing and relevant excessive deep implantation in the ventricle. In the last case, we assume that the initial deep implant position into the LV outflow tract led the patient to have complete atrioventricular block in the postoperative period, requiring cardiopulmonary resuscitation. Three weeks after surgery, severe aortic regurgitation caused by a paravalvular leak was detected. During reoperation, a deep positioning was confirmed, requiring explantation and replacement with a different prosthesis. Of the 6 late explantations (conducted 50-169 days after implantation), 5 were due to prosthetic valve endocarditis and 1 to an aorta-right ventricle fistula with progressive shunt requiring repair.

Recent studies have reported a decrease in the requirement for reoperation corresponding to increased experience with the Perceval and other sutureless valves, and reflecting overall and institutional learning curves. ${ }^{13-15}$ The Perceval valve can even be repositioned after balloon dilation in the case of supra-annular malpositioning as the result of an excessively rapid release of the prosthesis in the aorta or incomplete annular visualization. ${ }^{14}$ To date, midterm results from studies with sutureless valves have shown excellent hemodynamics and $100 \%$ freedom from structural valve deterioration. ${ }^{6,9,16}$

The assessment of functional status demonstrated a marked and stable improvement in NYHA class for most patients throughout the study period. Relative to baseline, $77.5 \%$ of all patients had an improvement in NYHA class of at least 1 level. To date, midterm results with sutureless valves have confirmed excellent hemodynamics and $100 \%$ freedom from reported structural valve deterioration. ${ }^{6,9,17}$

Stroke rates were $2.2 \%$ at 30 days and $0.8 \%$ in the late period, resulting in an overall incidence of $3.0 \%$ at 1 year. These findings are in line with the GARY registry, which reported in-hospital stroke rates of $1.9 \%$ and $2.9 \%$ in patients undergoing isolated and combined surgical AVR, respectively. At 1 year, the incidences reported for the same groups of patients were $3.0 \%$ and $4.5 \%$, respectively. ${ }^{13}$

PMI is a known complication after surgical AVR and transcatheter aortic valve implantation (TAVI). The rate of PMI as a result of third-degree atrioventricular block in our study $(9.6 \%)$ is similar to that reported by Matthews and coworkers. ${ }^{17}$ In their article on best evidence, taken from 7 single-center, retrospective observational case series, the incidence after conventional AVR ranged from $3.0 \%$ to $11.8 \%$. The rate of PMI in our study is higher than that in a retrospective observational study of 137 patients undergoing AVR with the Perceval valve (3.6\% at a median 6-month follow-up; range, 1-18 months) but may reflect differences in the length of follow-up. ${ }^{18}$ Known risk factors for PMI after AVR include pulmonary hypertension, preoperative anemia, age greater than 75 years, previous myocardial infarction, and preoperative rhythm disturbance. ${ }^{17,19}$ The rate of PMI in the CAVALIER study may be related in part to the risk profile of the patients. An additional factor may be the "learning-curve effect" in terms of procedural implanting steps and sizing. Furthermore, the high number of centers involved in the study, with the corresponding variability in operator experience and protocols for management of rhythm disorder, may represent other confounding factors. Indeed, some centers prefer a "watchful waiting" policy for as long as 10 days after surgery, whereas others favor $\mathrm{PMI}$ as soon as the cardiac rhythm disorder cannot be converted in the operating room. The mechanisms of the occurrence of new rhythm disorders after TAVI, as well as after sutureless valve implantation, need further studies to identify specific risk factors.

To date, TAVI is the intervention of choice in patients with aortic stenosis who are not operative candidates. The ongoing Surgical replacement and Transcatheter Aortic Valve Implantation (NCT01586910) and Placement of Aortic Transcatheter Valve 2 (NCT01314313) trials will evaluate the noninferiority of TAVI versus conventional surgery in intermediate-risk patients. If noninferiority is demonstrated, aortic stenosis therapy will likely change. In this clinical setting, TAVI may be approved for use in lower-risk patients. ${ }^{20}$ Currently, the Perceval valve is indicated for all adults with a diagnosis of aortic valve stenosis or stenosis with insufficiency. The choice of proceeding with surgical AVR or TAVR is still based on multiple variables, to be discussed by the heart team, including surgical risk, patient frailty, and comorbidities. No specific indications other than the current guidelines with regard to patient risk profile are currently given for the use of the sutureless bioprosthesis. ${ }^{21}$ The sutureless valve may be the treatment of choice for cases in which surgery can be safely performed, regardless of risk profile because of its superior midterm survival and lower morbidity, particularly paravalvular leak, relative to TAVI. In addition, MICS is greatly facilitated by the design of the Perceval valve, and reduction of procedure times when performing concomitant procedures makes it an attractive option relative to standard AVR. ${ }^{22}$

\section{Study Limitations}

The main limitation of this study is the lack of a control group receiving conventional valves. A planned large prospective, randomized, controlled trial comparing the Perceval valve with the traditional standard aortic replacement will address this aspect. 


\section{Conclusions}

The Perceval sutureless valve resulted in low rates of cardiac-related death, stroke, endocarditis, major paravalvular leaks, and valve explantations at 1 year in an intermediate-risk population undergoing AVR. Echocardiographic results showed stable reduction of gradients and a reduction in LV mass. Rates of paravalvular leak were low and stable from discharge out to 1 year. Indeed, NYHA class improved in more than three-quarters of the patients and remained stable during follow-up. These data support the safety and efficacy to 1 year of the Perceval sutureless valve in this intermediate-risk population. Fiveyear follow-up of the full patient cohort from CAVALIER is currently ongoing, and it will provide further assessment of the long-term valve performance.

\section{Conflict of Interest Statement}

T.F., B.M., and F.L. have disclosed financial relationships with Sorin Group. S.G. is a Sorin Group employee. All other authors have nothing to disclose with regard to commercial support.

You can watch a Webcast of this AATS meeting presentation by going to: http://webcast.aats.org/2015/Video/Wednesday/ 04-29-15_6B_0753_Fischlein.mp4.

Authors express gratitude to the CAVALIER Trial Investigators (listed in Appendix) for their contribution to the study and to Mara Chiaro (Sorin Group) for her technical support.

\section{References}

1. Flameng W, Herregods MC, Hermans H, Van der Mieren G, Vercalsteren M, Poortmans G, et al. Effect of sutureless implantation of the Perceval S aortic valve bioprosthesis on intraoperative and early postoperative outcomes. J Thorac Cardiovasc Surg. 2011;142:1453-7.

2. Folliguet TA, Laborde F, Zannis K, Ghorayeb G, Haverich A, Shrestha M. Sutureless Perceval aortic valve replacement: results of two European centers. Ann Thorac Surg. 2012;93:1483-8.

3. Santarpino G, Pfeiffer S, Schmidt J, Concistrè G, Fischlein T. Sutureless aortic valve replacement: first-year single center experience. Ann Thorac Surg. 2012; 94:504-8; discussion 508-9.

4. Shrestha M, Timm R, Höffeler K, Koigeldiyev N, Khaladi N, Hagl C, et al. Minimally invasive aortic valve replacement with self-anchoring Perceval valve. J Heart Valve Dis. 2013;22:230-5.

5. Phan K, Tsai YC, Niranjan N, Bouchard D, Carrel TP, Dapunt OE, et al. Sutureless aortic valve replacement: a systematic review and meta-analysis. Ann Cardiothorac Surg. 2015;4:100-11.

6. Meuris B, Flameng WJ, Laborde F, Folliguet TA, Haverich A, Shrestha M. Five year results of the pilot trial of a sutureless valve. J Thorac Cardiovasc Surg. 2015; 150:84-8.

7. Laborde F, Fischlein T, Hakim-Meibodi K, Misfeld M, Carrel T, Zembala M, et al. Clinical and haemodynamic outcomes in 658 patients receiving the Perceval sutureless aortic valve: early results from a prospective European multicentre study (the Cavalier Trial) $\dagger$. Eur J Cardiothoracic Surg. 2016;49: 978-86.

8. Shrestha M, Folliguet TA, Pfeiffer S, Meuris B, Carrel T, Bechtel M, et al. Aortic valve replacement and concomitant procedures with the Perceval valve: results of European trials. Ann Thorac Surg. 2014;98:1294-300.

9. Shrestha M, Fischlein T, Meuris B, Flameng W, Carrel T, Madonna F, et al. European multicentre experience with the sutureless Perceval valve: clinical and haemodynamic outcomes up to 5 years in over 700 patients $\uparrow$. Eur $J$ Cardiothoracic Surg. 2016;49:234-41.

10. Akins CW, Miller DC, Turina MI, Kouchoukos NT, Blackstone EH, Grunkemeier GL, et al; Councils of the American Association for Thoracic Surgery; Society of Thoracic Surgeons; European Association for Cardio-Thoracic Surgery; Ad Hoc Liaison Committee for Standardizing Definitions of Prosthetic Heart Valve Morbidity. Guidelines for reporting mortality and morbidity after cardiac valve interventions. J Thorac Cardiovasc Surg. 2008;135:732-8.

11. European Medicines Agency. Guidelines of the International Conference on Harmonisation of Technical Requirements for Pharmaceuticals for Human Use (ICH). Available at: http://www.ich.org/fileadmin/Public_Web_Site/ICH_Products/ Guidelines/Efficacy/E6/E6_R1_Guideline.pdf. Accessed February 11, 2016.

12. Mohr FW, Holzhey D, Möllmann H, Beckmann A, Veit C, Figulla HR, et al. The German Aortic Valve Registry: 1-year results from 13,680 patients with aortic valve disease. Eur J Cardiothorac Surg. 2014;46:808-16.

13. Permanyer E, Estigarribia AJ, Ysasi A, Herrero E, Semper O, Llorens R. The $3 f$ Enable sutureless bioprosthesis: early results, safeguards, and pitfalls. J Thorac Cardiovasc Surg. 2015;149:1578-83.

14. Santarpino G, Pfeiffer $S$, Concistrè G, Fischlein T. A supra-annular malposition of the Perceval S sutureless aortic valve: the ' $\chi$-movement' removal technique and subsequent reimplantation. Interact Cardiovasc Thorac Surg. 2012;15 280-1.

15. Breitenbach I, Wimmer-Greinecker G, Bockeria LA, Sadowski J, Schmitz C, Kapelak B, et al. Sutureless aortic valve replacement with the Trilogy Aortic Valve System: multicenter experience. J Thorac Cardiovasc Surg. 2010;140: 878-84. 884.e1.

16. Haverich A, Wahlers TC, Borger MA, Shrestha M, Kocher AA, Walther T, et al Three-year hemodynamic performance, left ventricular mass regression, and prosthetic-patient mismatch after rapid deployment aortic valve replacement in 287 patients. J Thorac Cardiovasc Surg. 2014;148:2854-61.

17. Matthews IG, Fazal IA, Bates MG, Turley AJ. In patients undergoing aortic valve replacement, what factors predict the requirement for permanent pacemaker implantation? Interact Cardiovasc Thorac Surg. 2011;12:475-9.

18. Gilmanov D, Miceli A, Bevilacqua S, Farneti P, Solinas M, Ferrarini M, et al Sutureless implantation of the Perceval S aortic valve prosthesis through right anterior minithoracotomy. Ann Thorac Surg. 2013;96:2101-8.

19. Kogan A, Sternik L, Beinart R, Shalabi A, Glikson M, Spiegelstein D, et al. Permanent pacemaker insertion following isolated aortic valve replacement before and after the introduction of TAVI. Pacing Clin Electrophysiol. 2015;38:424-30.

20. Haussig S, Linke A. Transcatheter aortic valve replacement should be expanded to lower-risk and younger patients. Circulation. 2014;130:2321-31.

21. Nishimura RA, Otto CM, Bonow RO, Carabello BA, Erwin JP III, Guyton RA, et al; American College of Cardiology/American Heart Association Task Force on Practice Guidelines. 2014 AHA/ACC guideline for the management of patients with valvular heart disease: executive summary: a report of the American College of Cardiology/American Heart Association Task Force on Practice Guidelines. J Am Coll Cardiol. 2014;63:2438-88. Erratum in: J Am Coll Cardiol. 2014;63:2489.

22. Santarpino G, Pfeiffer S, Jessl J, Dell'Aquila AM, Pollari F, Pauschinger M, et al Sutureless replacement versus trans catheter valve implantation in aortic valve stenosis: a propensity-matched analysis of 2 strategies in high-risk patients. $J$ Thorac Cardiovasc Surg. 2014;147:561-7.

Key Words: aortic valve, aortic valve replacement, bioprosthesis, sutureless

\section{Discussion}

Dr John S. Ikonomidis (Charleston, SC). Congratulations on an excellent presentation. This is perhaps the largest report of sutureless valves in publication, so it is of considerable interest. This prospective study is very well performed and presented but suffers from the lack of a control group of open sutured aortic valve replacements. In addition to this point, I have several questions. 
First, the average stay in this series was $12 \pm 7.4$ days. With the understanding that in this data set the patients were $40 \%$ octogenarian with a mean STS score of 7 , can you comment on what I would perceive to be a somewhat prolonged hospital stay relative to a short cardiac surgical procedure?

Dr Fischlein. I think it's because of the different system and also reimbursement system in Europe, especially in Germany. Normally we have a hospital stay ranging between 6 and 12 days, and all those patients are going postoperatively for rehabilitation; especially in this old group, you have no chance to send them home, so I think this is reason why. We do not have, let's say, a hotel just very near the hospital where we could send those patients similar to what I see it is done here in the United States very often.

Dr Ikonomidis. Can you comment on the stroke rate? I saw that it was $3.3 \%$, which strikes me as perhaps being a little bit high. Is there anything particular to placement of a Perceval valve that could explain that?

Dr Fischlein. I think it's a little bit of a mistake. It's about $3 \%$ after 1 year. I must say it's a high age group, however, and if you compare it, for example, to the German GARY registry, we also have this kind of incidence, I think even higher, about a $4 \%$ to $5 \%$ stroke rate, within the first year of follow-up after aortic valve replacement.

Dr Ikonomidis. So one of the challenges related to transcatheter valves and, to some extent, sutureless valves, is the requirement for PMI afterward. In this particular series, the 30-day PMI rate was $8.1 \%$, and then there was an additional $1.5 \%$ to a maximum of $9.6 \%$ at 1 year.

Could you comment on the things that you have learned during the course of this study related to the implantation of these valves that might educate us with regard to how to implant them to reduce the incidence of heart block?

Dr Fischlein. Thank you very much for the question. It was mentioned today already. I think, of course, we all went through a learning curve. Maybe there's also implantation or oversizing, and because of the radial forces, it might induce atrioventricular block, because we looked at that also in our institution, and what we have seen also is that a lot of those patients already had preoperative rhythm disturbances, such as right branch block. And we tried also to reduce the pressure of the ballooning after deployment of the prosthesis; that might also influence atrioventricular block incidence. This is what I think we have learned during this period. Maybe we have to reduce the ballooning. In our institution, we have a lower incidence of PMI.

Dr Ikonomidis. Congratulations on a nice presentation.

Dr Vinod H. Thourani (Atlanta, Ga). Michael Mack presented the TAVR results from the transcatheter valve therapy database; where he showed a STS predicted risk of mortality of 7, the same score that you have. The CoreValve trial showed in their high-risk patients, I think with the data that Adams and Reardon presented, an STS score of 7. You presented a study today with an STS score also of 7. It would be great for us to know your thoughts on whether these patients with a STS score of 7 to 8 are going to undergo TAVR or a sutureless valve implantation? It will be great to hear the perspective of the Europeans on this topic.

Dr Fischlein. Of course we have to deal with a very old patient group, like everywhere. But in the beginning in our institution, we implanted this valve mainly, let's say, in older patients, higher-risk patients, because of the advantage of reducing ischemic time and clamping time. We do think that this prosthesis is actually an optimal choice for these kind of gray-zone patients. So I think it's a very good technique to use a sutureless valve for patients whose condition is, let's say, too bad for conventional aortic valve replacement but too good for a TAVI procedure. In the end, however, as soon as we get more and more data about that, I'm sure that we also will implant this kind of prosthesis in all patient risk groups and also in younger patients.

Dr Thorsten Wahlers (Cologne, Germany). If you compare these data with the Intuity valve, PMI rates are about twice as high, because with the Intuity you achieve a rate of around $4 \%$. The Intuity is a valve that is placed $100 \%$ supra-annularly. Can you speculate whether the implantation height of the Perceval valve might vary in between patients and relate to the PMI rate?

Dr Fischlein. Of course, we only can speculate. I know that also in the beginning of the implantation period for the Intuity, they also had a higher incidence of PMI. But I'm also wondering about that, I must say, because the positioning of the valve and the deployment of this stent are actually in the left ventricular outflow tract, which could also induce rhythm disturbances. In the end, I must say that I do not have an answer as to why we see a higher incidence in the Perceval group than with the Intuity valve. 


\section{APPENDIX}

\section{CAVALIER Trial Investigators}

The authors express gratitude to the following CAVALIER Trial Investigators for their contribution to the study:

Thierry Folliguet, ${ }^{\text {a }}$ Kostantinos Zannis, ${ }^{a}$ Steffen Pfeiffer, ${ }^{b}$ Giuseppe Santarpino, ${ }^{b}$ Malakh Shrestha, ${ }^{\text {c Samir }}$

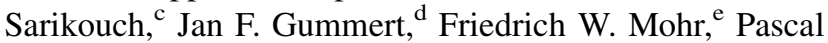
Dohmen, ${ }^{\mathrm{e}}$ Mario Stalder, ${ }^{\mathrm{f}}$ Eva Roost ${ }^{\mathrm{f}}{ }$ Krzysztof Filipiak, ${ }^{\mathrm{g}}$ Tomasz Niklewski, ${ }^{\mathrm{g}}$ Xavier Roques, ${ }^{\mathrm{h}}$ Willem J. Flameng, ${ }^{\mathrm{i}}$ Axel M. M. Laczkovics, ${ }^{\mathrm{j}}$ Matthias Bechtel, ${ }^{\mathrm{j}}$ Alain G. Prat, ${ }^{\mathrm{k}}$ Carlo Banfi, ${ }^{k}$ Otto E. Dapunt, ${ }^{1}$ Harald C. Eichstaedt, Wolfgang Harringer, ${ }^{\mathrm{m}}$ Ulrike Carstens-Fitz, ${ }^{\mathrm{m}}$ Tom J. Spyt, ${ }^{\mathrm{n}}$ Jan Gerhard Wimmer-Greinecker, ${ }^{\circ}$ Matthias Machner, ${ }^{\circ}$ Erwin S. H. Tan, ${ }^{\mathrm{p}}$ Filip P. A. Casselman, ${ }^{\mathrm{q}}$ Alaaddin Yilmaz, ${ }^{\mathrm{r}}$ Uday Sonker, ${ }^{r}$ Sabine Bleiziffer, ${ }^{\text {s }}$ Peter J. Oberwalder, Alfred A. Kocher, ${ }^{\text {u Rainald Seitelberger, }{ }^{\text {u }} \text { Hendrik Treede, }}{ }^{\text {v }}$ Leonard Conradi, ${ }^{\text {v }}$ Riccardo Cocchieri, ${ }^{\text {w }}$ Bas De Mol, ${ }^{w}$ Jean-Christian Roussel, ${ }^{\mathrm{x}}$ Philippe Despins, ${ }^{\mathrm{x}}$ Heinz G. Jakob, ${ }^{\mathrm{y}}$ and Daniel Wendt. ${ }^{\mathrm{y}}$

From the following institutions: the ${ }^{\text {a Cardiac Medico- }}$ Surgical Department, Institute Mutualiste Montsouris, Paris, France; the ${ }^{\mathrm{b}}$ Department of Cardiac Surgery, Paracelsus Medical University, Klinikum Nürnberg, Nuremberg, Germany; the ${ }^{\mathrm{c}}$ Department of Cardio-thoracic, Transplantation \& Vascular Surgery, Hannover Medical School, Germany; the ${ }^{\mathrm{d}}$ Klinik, Herz- und Diabeteszentrum, Bad Oeynhausen, Germany; the ${ }^{\mathrm{e}}$ Klinik fur Herzchirurgie,
Herzzentrum der Universität Leipzig, Leipzig, Germany; ${ }^{\mathrm{f}}$ Inselspital, University of Bern, Bern, Switzerland; the ${ }^{\text {g}}$ Silesian University Center for Heart Disease, Zabrze, Poland; the ${ }^{i}$ Hôpital Cardiologique Du Haut- Lévêque, Pessac, France; the ${ }^{\mathrm{h}}$ Department of Cardiac Surgery, U.Z. Gasthuisberg, Leuven, Belgium; the ${ }^{\mathrm{i}}$ Department of Cardiothoracic Surgery, Ruhr University of Bochum, Bochum, Germany; ${ }^{j}$ Centre Hospitalier Regional Universitaire, Lille, France; ${ }^{1}$ Klinikum Oldenburg, Department of Cardiovascular Surgery, Oldenburg, Germany; the ${ }^{\mathrm{m}}$ Department of Thoracic and Cardiovascular Surgery, Klinikum Braunschweig, Braunschweig, Germany; the ${ }^{\mathrm{n}}$ Regional Cardiothoracic Unit, Genfield General Hospital, Leicester, UK; ${ }^{\circ}$ Herz und Gefäßzentrum, Bad Bevensen, Germany; ${ }^{\mathrm{P}}$ Catharina Ziekenhuis, Eindhoven, Netherlands; the ${ }^{\mathrm{q}}$ Department of Cardiovascular and Thoracic Surgery, OLV Clinic, Aalst, Belgium; ${ }^{\mathrm{r}}$ Saint Antonius Hospital, Nieuwegein, Netherlands; 'German Heart Center, Munich, Germany; the ${ }^{t}$ Department of Cardiac Surgery, Medical School Graz, Graz, Austria; the "Department of Cardiothoracic Surgery, Medical University, Vienna, Austria; ${ }^{v}$ Universitäres Herzzentrum Hamburg $\mathrm{GmbH}$,

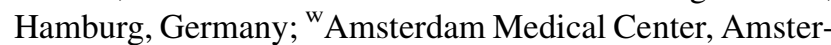
dam, Netherlands; ${ }^{\mathrm{x}}$ Centre Hospitalier Universitaire, Nantes, France; and the ${ }^{\mathrm{y}}$ Department of Thoracic and Cardiovascular Surgery, University of Essen, West German Heart Center, Essen, Germany. 


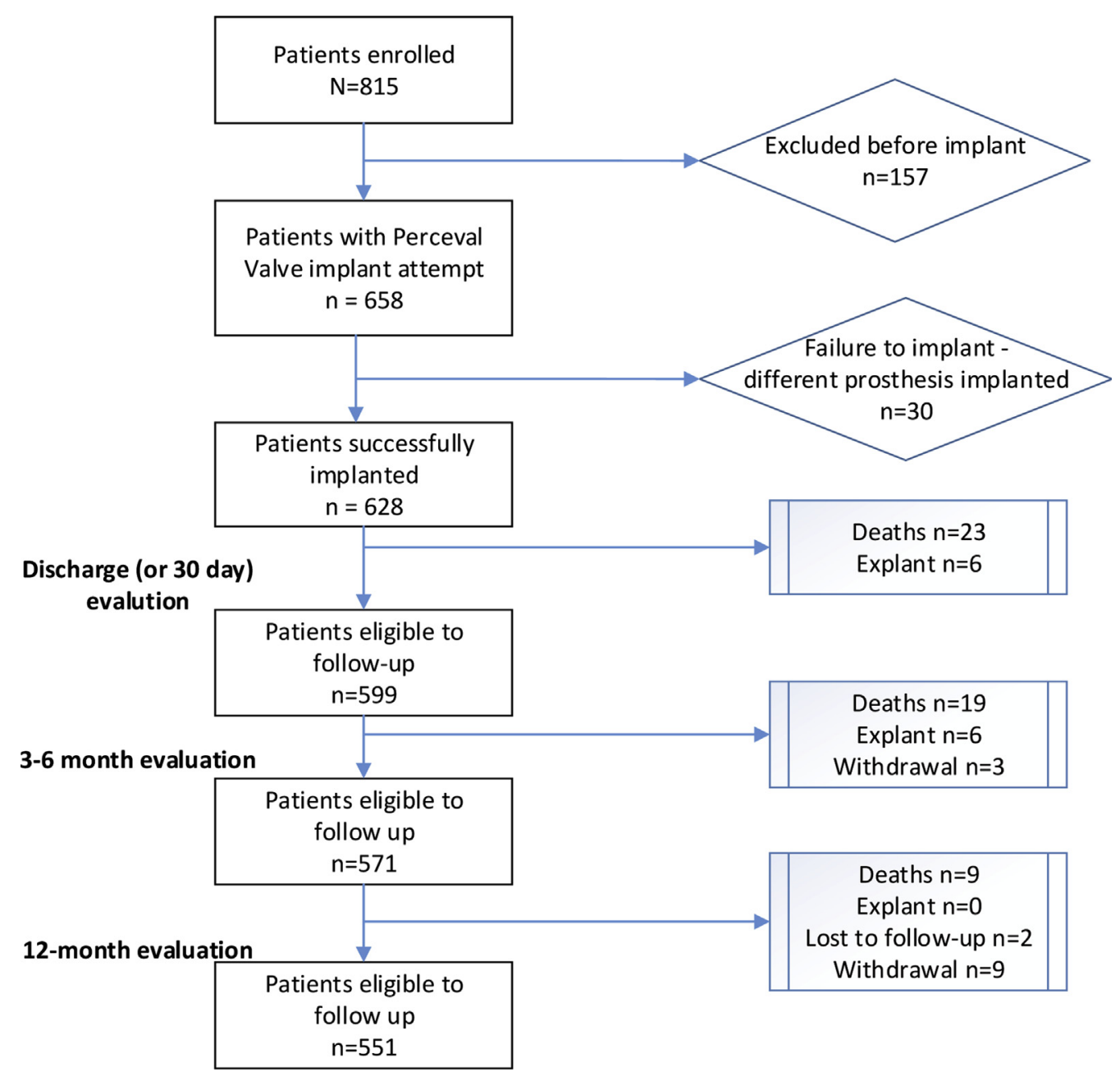

FIGURE E1. Study flow chart. 
TABLE E1. Study inclusion and exclusion criteria

Inclusion criteria

1. Age $\geq 65$ y

2. Subjects with aortic valve stenosis or stenosis with insufficiency

3. Subjects in whom preoperative evaluation indicated the need for native or prosthetic aortic valve replacement with a biologic prosthesis

4. Subjects willing to sign the informed consent

5. Subjects willing to undergo all the medical follow-ups and echocardiographic examinations and laboratory tests that form part of this present protocol

\section{Exclusion criteria}

1. Subjects involved in any other clinical study for drugs or devices

2. Subjects with a previously implanted Perceval prosthesis, within the clinical study, that requires replacement

3. Subjects with previous implantation of valve prostheses or annuloplasty ring not being replaced by the study valve

4. Subjects requiring simultaneous cardiac procedures, apart from septal myectomy, coronary artery bypass grafting, or both

5. Subjects who require double or multiple valve replacement or repair in whom the mitral, tricuspid, or pulmonic valve would be replaced with a non-Perceval valve or repaired

6. Subjects with aneurysmal dilation or dissection of the ascending aortic wall

7. Subjects needing nonelective intervention

8. Subjects with active endocarditis

9. Subjects with active myocarditis

10. Subjects with congenital bicuspid aortic valve

11. Subjects with aortic root enlargement with a ratio between the diameter of the sinotubular junction and the annulus diameter, as assessed by TTE, greater than 1.3

12. Subjects with aortic root height (measured from aortic annulus to sinotubular junction) of at least $21 \mathrm{~mm}$ for size $\mathrm{S}(21 \mathrm{~mm})$, at least $22.5 \mathrm{~mm}$ for size $\mathrm{M}(23 \mathrm{~mm})$, at least $24 \mathrm{~mm}$ for size L (25 mm), and at least $25 \mathrm{~mm}$ for size XL (27 mm)

13. Subjects with myocardial infarction within 90 days before the planned valve implant surgery

14. Subjects with known hypersensitivity to nickel alloys

15. Subjects involved in any other clinical study for drugs or devices

16. Subjects who are prison inmates, institutionalized, or unable to give informed consent

17. Subjects with major or progressive noncardiac disease that, in the investigator's experience, results in a life expectancy of less than $1 \mathrm{y}$, or in whom the implantation of the device produces an unacceptable increased risk to the patient

18. Subjects undergoing renal dialysis for chronic renal failure or with hyperparathyroidism

19. Subjects with an acute preoperative neurological deficit, myocardial infarction, or cardiac event that has not returned to baseline or stabilized at least $30 \mathrm{~d}$ before the planned valve implant surgery 
TABLE E2. Hematologic parameters at 3- to 6-month and 1-year follow-ups

\begin{tabular}{|c|c|c|c|c|c|c|c|}
\hline Variable & Total $\mathbf{N}$ & $\mathbf{n}$ & Mean & Median & SD & Minimum & Maximum \\
\hline \multicolumn{8}{|c|}{ Red blood cells $\left(10^{12}\right.$ cells $/ \mathrm{L} ;$ reference range, $4.15-4.90 \times 10^{12}$ cells $\left./ \mathrm{L}\right)$} \\
\hline Preoperative & 658 & 647 & 4.2 & 4.2 & 0.5 & 1.8 & 5.6 \\
\hline Discharge (or $30 \mathrm{~d}$ ) & 615 & 601 & 3.6 & 3.5 & 0.5 & 2.5 & 10.5 \\
\hline Follow-up 3-6 mo & 580 & 477 & 4.3 & 4.4 & 0.5 & 2.4 & 6.0 \\
\hline Follow-up 12 mo & 554 & 465 & 4.3 & 4.4 & 0.5 & 2.5 & 6.0 \\
\hline \multicolumn{8}{|c|}{ White blood cells $\left(10^{9}\right.$ cells $/ \mathrm{L}$; reference range, $4.3-10.8 \times 10^{9}$ cells $\left./ \mathrm{L}\right)$} \\
\hline Preoperative & 658 & 653 & 6.8 & 6.5 & 2.1 & 2.0 & 21.6 \\
\hline Discharge (or $30 \mathrm{~d}$ ) & 615 & 607 & 8.9 & 8.5 & 2.8 & 2.1 & 20.8 \\
\hline Follow-up 3-6 mo & 580 & 478 & 7.2 & 7.0 & 2.0 & 1.9 & 17.6 \\
\hline Follow-up 12 mo & 554 & 466 & 7.3 & 7.1 & 1.9 & 2.9 & 14.7 \\
\hline \multicolumn{8}{|c|}{ Hemoglobin (g/dL; reference range, $12-18 \mathrm{~g} / \mathrm{dL})$} \\
\hline Preoperative & 658 & 653 & 12.6 & 12.7 & 1.7 & 6.3 & 21.0 \\
\hline Discharge (or $30 \mathrm{~d}$ ) & 615 & 607 & 10.6 & 10.6 & 1.3 & 6.1 & 15.5 \\
\hline Follow-up 3-6 mo & 580 & 478 & 12.4 & 12.5 & 1.5 & 6.4 & 16.9 \\
\hline Follow-up 12 mo & 554 & 467 & 13.0 & 13.0 & 1.4 & 7.8 & 18.0 \\
\hline \multicolumn{8}{|c|}{ Hematocrit ( $\%$; reference range, $37 \%-52 \%)$} \\
\hline Preoperative & 658 & 652 & $37.6 \%$ & $37.9 \%$ & $4.4 \%$ & $19.9 \%$ & $52.2 \%$ \\
\hline Discharge (or $30 \mathrm{~d}$ ) & 615 & 606 & $32.3 \%$ & $32.0 \%$ & $3.8 \%$ & $23.0 \%$ & $46.5 \%$ \\
\hline Follow-up 3-6 mo & 580 & 478 & $37.9 \%$ & $38.1 \%$ & $4.1 \%$ & $21.8 \%$ & $50.0 \%$ \\
\hline Follow-up 12 mo & 554 & 466 & $39.0 \%$ & $39.0 \%$ & $3.9 \%$ & $26.0 \%$ & $52.0 \%$ \\
\hline \multicolumn{8}{|c|}{ Platelet count $\left(10^{9}\right.$ cells $/ \mathrm{L} ;$ reference range, $150-350 \times 10^{9}$ cells $\left./ \mathrm{L}\right)$} \\
\hline Preoperative & 658 & 653 & 220.8 & 212.0 & 67.1 & 66.0 & 526.0 \\
\hline Discharge (or $30 \mathrm{~d}$ ) & 615 & 606 & 194.8 & 177.5 & 97.8 & 20.3 & 863.0 \\
\hline Follow-up 3-6 mo & 580 & 477 & 184.5 & 178.0 & 68.9 & 25.0 & 544.0 \\
\hline Follow-up 12 mo & 554 & 465 & 188.4 & 182.0 & 61.8 & 44.0 & 476.0 \\
\hline \multicolumn{8}{|c|}{ Reticulocytes ( $\%$; reference range, $0.5 \%-2.5 \%)$} \\
\hline Preoperative & 658 & 414 & $1.2 \%$ & $1.1 \%$ & $0.5 \%$ & $0.3 \%$ & $4.1 \%$ \\
\hline Discharge (or $30 \mathrm{~d}$ ) & 615 & 367 & $2.4 \%$ & $2.2 \%$ & $1.2 \%$ & $0.5 \%$ & $10.9 \%$ \\
\hline Follow-up 3-6 mo & 580 & 447 & $1.2 \%$ & $1.0 \%$ & $1.4 \%$ & $0.2 \%$ & $28.2 \%$ \\
\hline Follow-up 12 mo & 554 & 437 & $1.1 \%$ & $1.1 \%$ & $0.6 \%$ & $0.1 \%$ & $8.2 \%$ \\
\hline \multicolumn{8}{|c|}{ Haptoglobin (mg/dL; reference range, $13-163 \mathrm{mg} / \mathrm{dL})$} \\
\hline Preoperative & 658 & 421 & 127.5 & 125.0 & 64.4 & 7.0 & 350.0 \\
\hline Discharge (or $30 \mathrm{~d}$ ) & 615 & 365 & 171.9 & 178.0 & 95.2 & 7.0 & 406.0 \\
\hline Follow-up 3-6 mo & 580 & 446 & 116.0 & 110.0 & 75.7 & 7.0 & 480.0 \\
\hline Follow-up 12 mo & 554 & 448 & 120.3 & 115.5 & 73.1 & 2.5 & 495.0 \\
\hline \multicolumn{8}{|c|}{ Lactase dehydrogenase (IU/L; reference range, 110-250 IU/L) } \\
\hline Preoperative & 658 & 509 & 222.7 & 206.4 & 76.8 & 73.9 & 872.0 \\
\hline Discharge (or $30 \mathrm{~d}$ ) & 615 & 433 & 420.0 & 399.4 & 125.7 & 162.0 & 942.0 \\
\hline Follow-up 3-6 mo & 580 & 461 & 320.9 & 308.0 & 90.0 & 128.0 & 811.0 \\
\hline Follow-up 12 mo & 554 & 456 & 292.8 & 280.5 & 82.1 & 104.3 & 783.4 \\
\hline
\end{tabular}

